\title{
Curriculum Exchange: Middle School Students Go Beyond Blackboards to Solve the Grand Challenges
}

\section{Mr. Austin Bates Talley, University of Texas, Austin}

Austin Talley is a Doctoral Candidate in the Mechanical Engineering Department at the University of Texas at Austin, a Cockrell Fellow, and a licensed Professional Engineer. His research focus is in design methodology with Universal Design and engineering education. He has received his B.S. from Texas A\&M University and M.S.E. from The University of Texas at Austin.

\section{Dr. Richard H. Crawford, University of Texas, Austin}

Dr. Richard H. Crawford is a Professor of Mechanical Engineering at The University of Texas at Austin and is the Temple Foundation Endowed Faculty Fellow No. 3. He is also Director of the Design Projects program in Mechanical Engineering. He received his B.S.M.E. from Louisiana State University in 1982, and his M.S.M.E. in 1985 and Ph.D. in 1989, both from Purdue University. He teaches mechanical engineering design and geometry modeling for design. Dr. Crawford's research interests span topics in computer-aided mechanical design and design theory and methodology. Dr. Crawford is co-founder of the DTEACh program, a "Design Technology" program for K-12, and is active on the faculty of the UTeachEngineering program that seeks to educate teachers of high school engineering.

\section{Dr. Christina Kay White, University of Texas, Austin}

Dr. Christina White completed her Doctoral degree from Teachers College, Columbia University where she studied engineering education. She is the director of the National Academy of Engineering Longhorn Grand Challenges Scholars \& K12 Partners Program at The University of Texas at Austin. Dr. White is also the director of an outreach program called Design, Technology, \& Engineering for All Children (DTEACh) which has reached more than 1000 teachers and 85,000 students. She is the lead inventor on a patent for assistive technology. Her current research includes innovative design-based pedagogy, humanitarian engineering, and ways to attract and retain traditionally underrepresented groups in engineering education. 


\title{
Curriculum Exchange: Middle School Students Go Beyond Blackboards to Solve the Grand Challenges
}

\begin{abstract}
Our program offers an integrated approach to engaging middle school students in activities that improve awareness and understanding of a range of STEM college and career pathways. The program is framed within the Grand Challenges of the $21^{\text {st }}$ Century identified by the National Academy of Engineering (NAE). The focus of this paper is the curriculum used for our afterschool Innovation Clubs. The Innovation Clubs use the LEGO ${ }^{\circledR}$ MINDSTORMS $^{\circledR}$ NXT robotics kits, augmented with other technical resources, to investigate solar and wind energy. We integrate additional hardware, such as solar panels, third-party sensors, and common construction materials, and teach ways to apply new software techniques as students evolve their programming skills. Overall, students are identifying and designing innovative engineering solutions to some of our world's most pressing problems. The curriculum includes the details of structured LEGO $^{\circledR}$ builds and specialized programming, curriculum design prompts, design challenge mats, and professional development documentation. This paper describes examples of the curriculum to give the reader a better understanding of the content, including detailed descriptions of the format of the structured builds. The goal of this paper is to disseminate to others the curriculum resources that were developed for this program.
\end{abstract}

\section{Introduction}

Now more than ever, there is a world-wide need for collaboration to solve major engineering challenges that must be addressed in order to maintain quality of life, national security, and a sustainable future ${ }^{1}$. To address these issues, the National Academies of Science and Engineering along with many others agree that the USA needs to produce more engineers and scientists ${ }^{2}$. Therefore, improvements to pre-engineering education are needed to attract more students to Science, Technology, Engineering, and Mathematics (STEM) pathways. This is the purpose of the Design Technology and Engineering for All Children (DTEACh) program that is offered by the Cockrell School of Engineering at The University of Texas at Austin. This program uses active learning with open-ended design projects to improve students' understanding of STEM concepts. This paper gives an overview of the curriculum of our afterschool program, Beyond Blackboards. We particularly focus on seven structured solar energy design and build activities. The layout of the components of the structured builds is discussed, as are examples of the general curriculum.

\section{Program Background}

For over 20 years, our DTEACh Professional Development Institutes (PDIs) for K-12 teachers have sought to enhance STEM concepts with active learning techniques ${ }^{3},{ }^{4}$. The program provides guidance to K-12 teachers on using design problems in their classrooms to teach applied mathematics and science. The PDIs teach engineering concepts through the use of everyday technology, directed laboratory activities, and design briefs. Since 1998 our program has used LEGO ${ }^{\circledR}$ MINDSTORMS ${ }^{\circledR}$ robotics as the focus for hands-on experiences. The program has its roots in engineering design theory and learning science research. To clearly demonstrate the effectiveness of this teaching approach, the entire program is taught using the methods the participants are expected to use in their classrooms. This curriculum exchange paper is presented as a part of dissemination of the program's research and resources; information about the program and past research can be found at our website and in past publications ${ }^{4,5,6,7,8}$. 


\section{Robotics}

Robotics technology has been shown to be an effective means of engaging students in meaningful design activities. In a study of a summer program using LEGO $^{\circledR}$ MINDSTORMS $^{\circledR}$ robotics, 10- to 13-year old students built submersible boats over 3.5 hours at a summer camp ${ }^{9}$. Many students let the materials drive their progress and engaged in trial and error designs, becoming frustrated during the process. Some students stayed within the problem but spent time planning and were able to generate designs. Some students spent time planning and worked towards extravagant designs, and were driven to creating designs that somehow outperformed others' designs. One student spent too much time in planning and was not able to engage in the evaluation aspects of design. Many students completed only two aspects of the design process and then proceeded to play with their designs ${ }^{9}$. This is construed as a negative, but has been used to promote redesign with younger children, whose play may be leveraged as an evaluation phase; students would interrupt their play when their design had a structural failure or to accommodate changes in the storyline of their play ${ }^{10}$. In other words, robotics "play" offers multiple teaching and learning opportunities.

The evaluation of our program shows substantial agreement with this example. The Beyond Blackboards curriculum discussed uses the LEGO ${ }^{\circledR}$ MINDSTORMS ${ }^{\circledR}$ Education NXT Base Set, and LEGO ${ }^{\circledR}$ MINDSTORMS $^{\circledR}$ Education Resource Set, and the LEGO ${ }^{\circledR}$ Renewable Energy Add-On Set ${ }^{11}$. The program has been deployed extensively in a rural Central Texas school district in three middle schools and eight elementary schools. The curriculum discussed herein has been used in afterschool programs during the spring semester. We have evaluated the program using surveys, observations, and focus groups. The results indicate that the percentage of participants with a positive attitude toward having a career as an engineer increased from $45 \%$ to $71 \%$ from the fall to the spring. Additionally, the participants expressed increased aspiration to go beyond high school and complete a bachelor's degree (from 19\% in the fall to $40 \%$ in the spring), while showing decreased uncertainty regarding their ultimate educational attainment (from $19 \%$ in the fall to $5 \%$ in the spring). Teachers who participated in the program perceived positive changes in themselves that were transferred to their approaches to and content in regular classroom instruction.

\section{Grand Challenges}

The curriculum is motivated by elements of the Engineering Grand Challenges of the $21^{\text {st }}$ Century identified by the National Academy of Engineering. Throughout human history, imagination has come to fruition through engineering, which has driven immense advances in civilization. These advances can be seen with significant engineering feats that drastically changed societies. Among the most notable are ships that created innovative channels for trade and travel; sanitation systems for improved health and quality of life; widespread development and distribution of electricity and water; automobiles and airplanes; telephones; computers; space exploration; and the Internet.

Reflecting on the $20^{\text {th }}$ century and looking forward in our first decade of the new millennium, the National Academy of Engineers (NAE) sought innovative ways to identify formidable challenges as the population grows and its needs and desires expand ${ }^{12}$. The NAE gathered a team of leading thinkers with a wide range of experiences who are dedicated to improving the quality of life around the globe. This team explored broad realms of human concern - sustainability, health, vulnerability, and joy of living - and generated 14 specific Grand Challenges that await engineering solutions, as shown in Figure 1. 


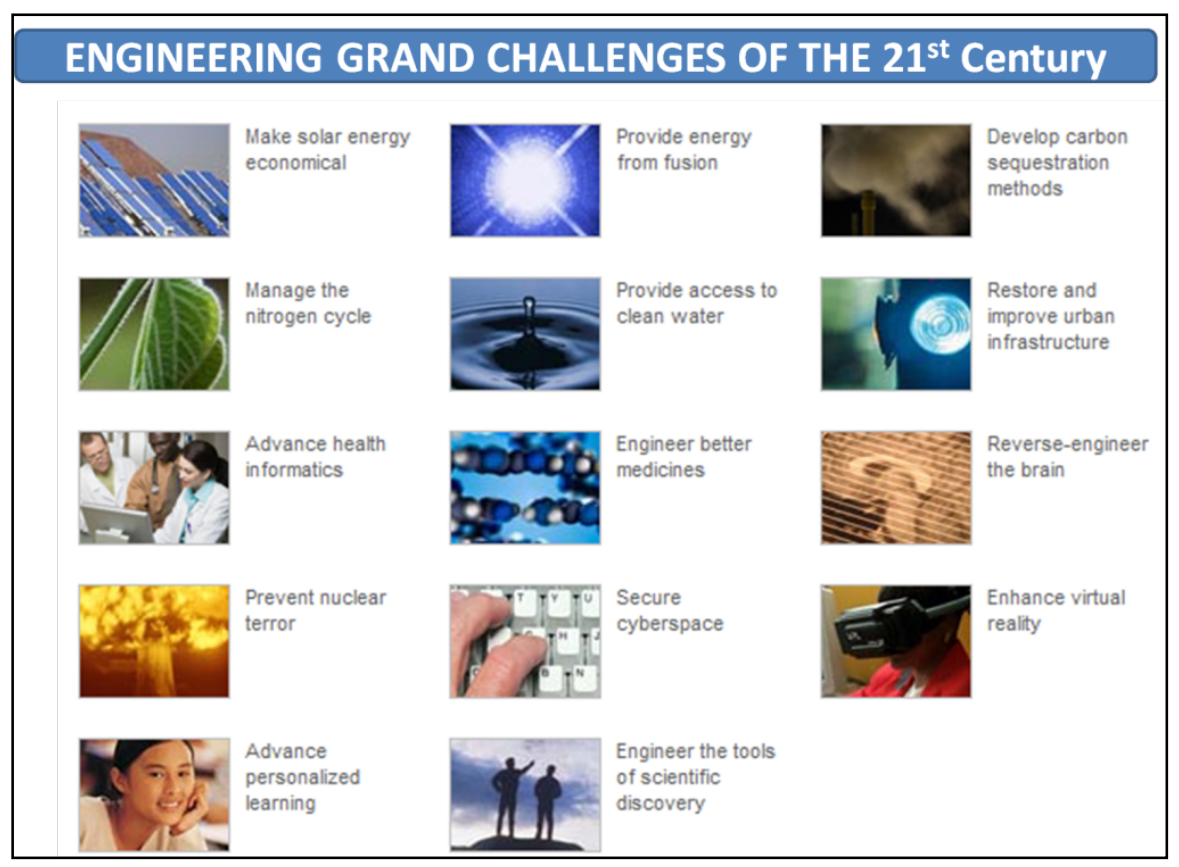

Figure 1: $21^{\text {st }}$ Century Engineering Grand Challenges ${ }^{12}$.

The curriculum and pedagogy of our program have evolved over the years to shift with the dynamic nature of engineering education. Our curriculum evolution now incorporates the Grand Challenges as the framework for designs. The curriculum described in this paper focuses on the challenge of "Making solar energy affordable".

\section{Curriculum Elements}

The curriculum includes the detailed structured LEGO ${ }^{\circledR}$ builds, specialized programming, curriculum design prompts, challenge mats, and professional development documentation. These elements are described below.

\section{Structured LEGO ${ }^{\circledR}$ Solar Builds}

For the solar based curriculum structured builds were created to provide the students with experiences with design process and the new hardware to ensure their success when tackling open ended design challenges. Structured builds were created for seven different products and ranged from basic to advanced assemblies, as shown in Table 1. The instructions for each build start with an overview picture and description of the build. Figure 2 shows the overview picture of the completed yardstick cable car. Next, the structured build provides a detailed materials list of all LEGO ${ }^{\circledR}$ and non-LEGO ${ }^{\circledR}$ items needed to complete the build. This materials list includes a picture and a written description of each component to help students learn common terminology when discussing the LEGO $^{\circledR}$ parts. Figure 3 shows a portion of the materials list of the yardstick cable car. 
Table 1: Structured Solar Builds

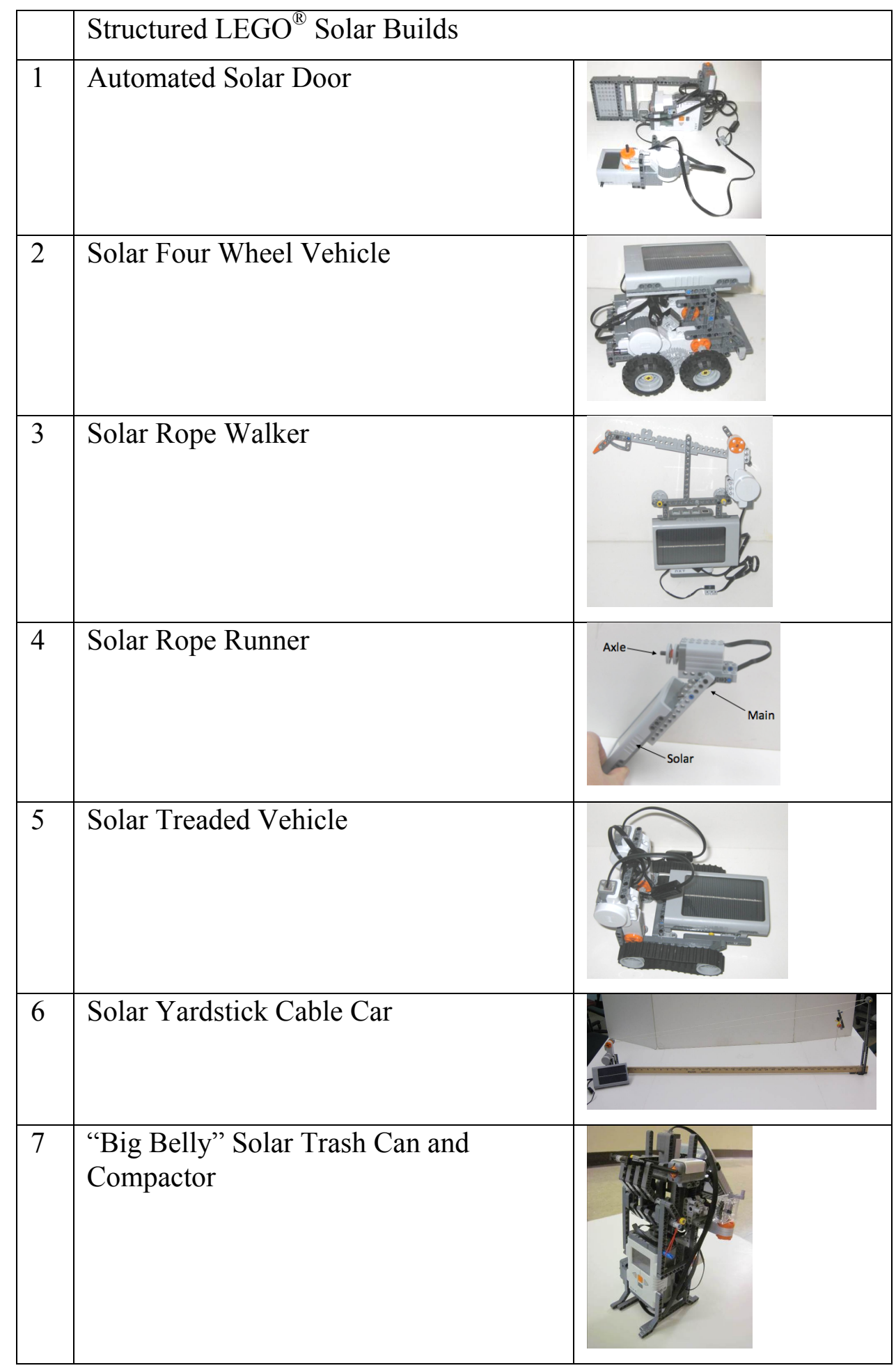




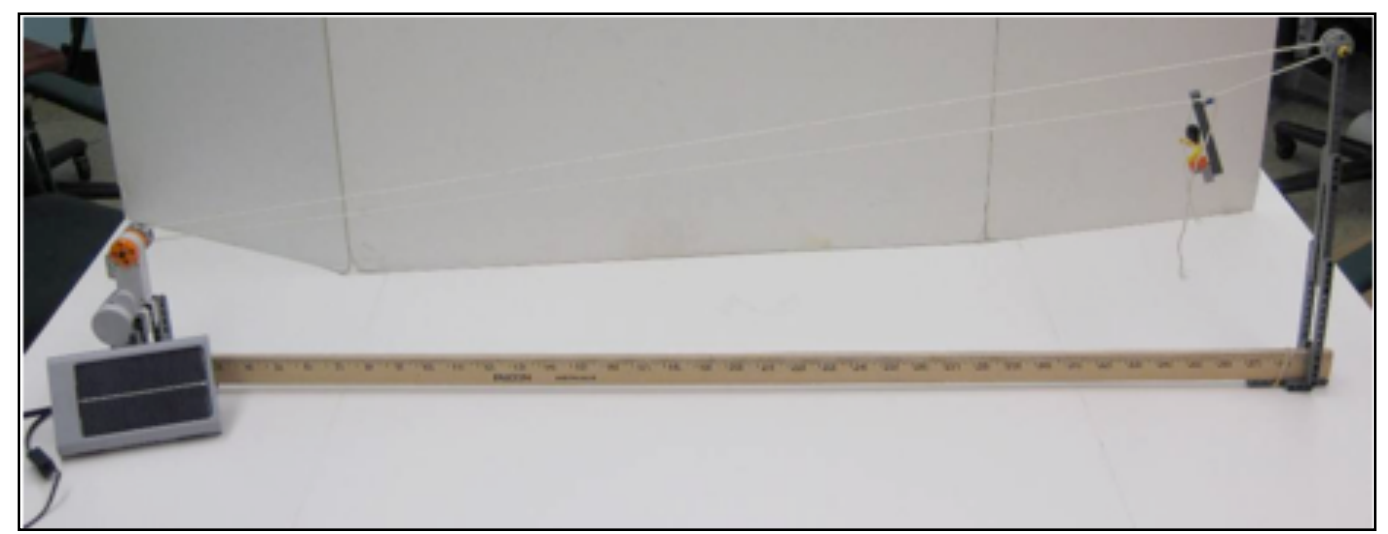

Figure 2: Yardstick cable car.

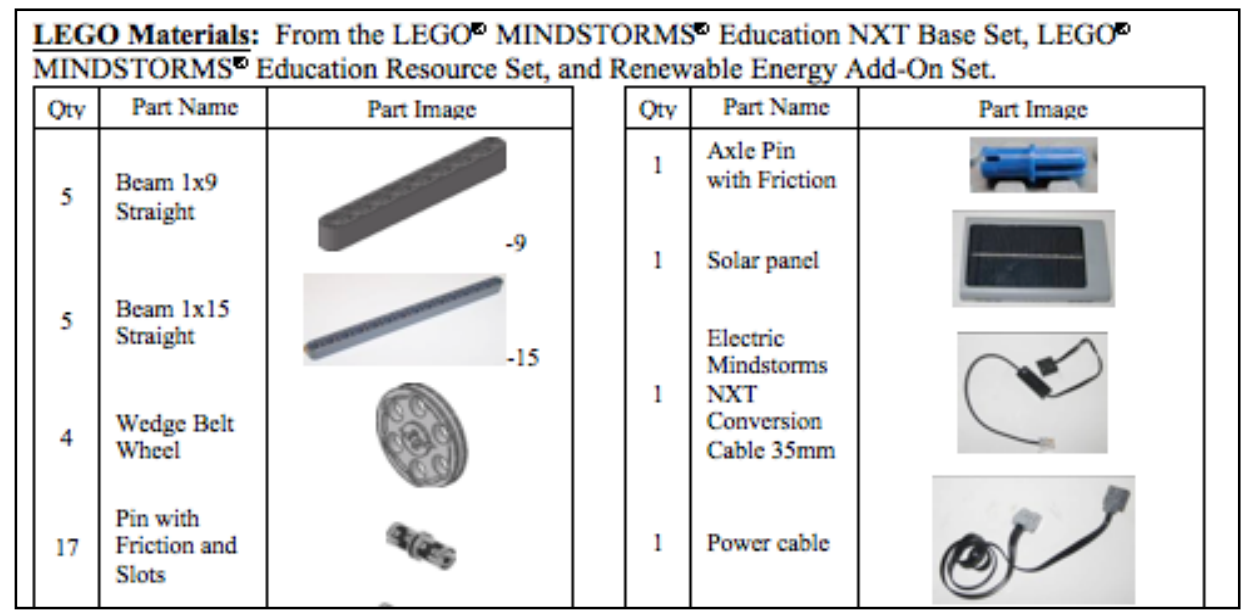

Figure 3: Example build materials list for the yardstick cable car.

The final section, the majority of the document, comprises the actual building instructions. For each step there is a written description of what needs to be done, a materials list for the step and a picture of the results of the step. An example is shown in Figure 4. 


\section{Pulley Assembly}

To construct the Pulley Assembly of the Yardstick Cable Car, please follow the instructions as below.
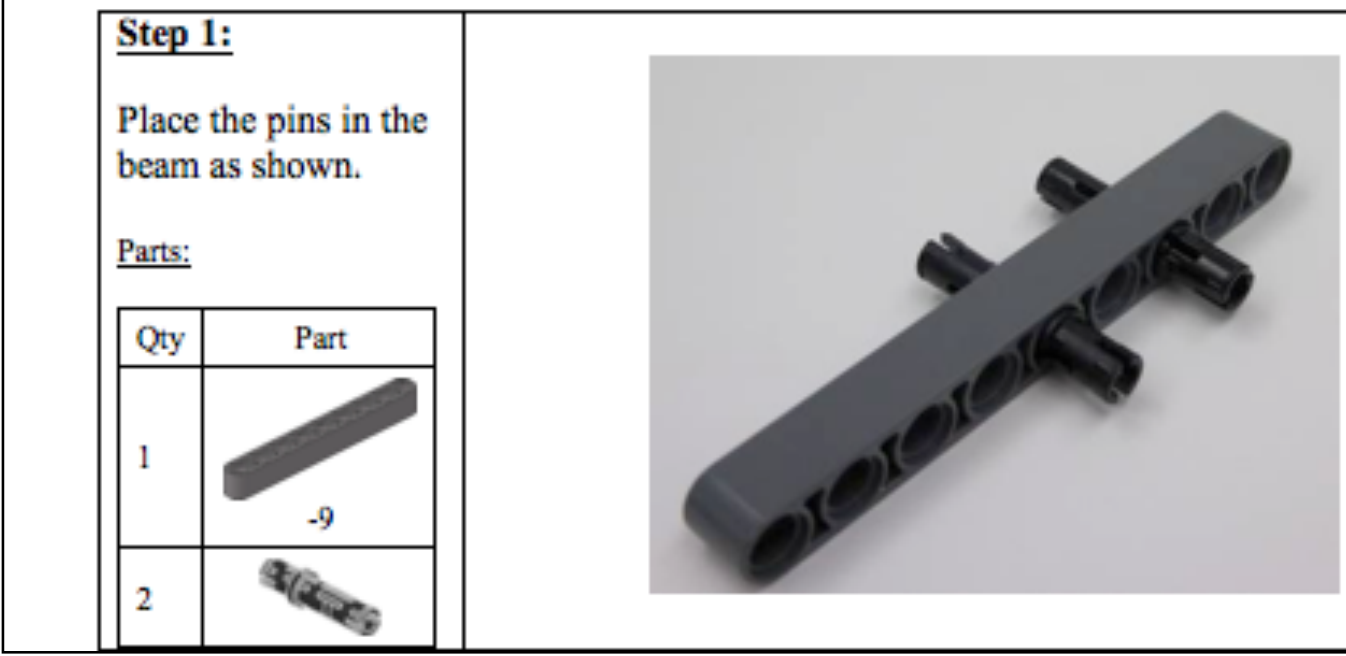

Figure 4: Detailed building instructions for yardstick cable car.

\section{Specialized Programming}

For the structured labs specialized program examples are provided for the more complex builds. Basic, intermediate and advanced builds are created and documented to help the students and teacher explore the performance of the devices. Figure 5 shows an example of one of the documented basic programs.

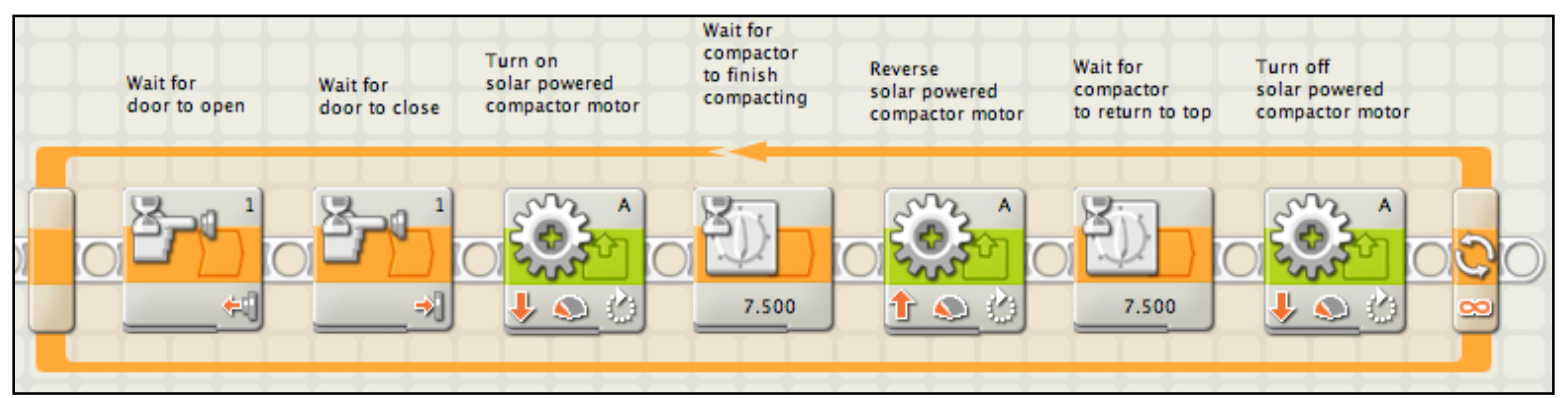

Figure 5: Documented program example for the Big Belly build.

\section{Challenge Mats}

As part of the curriculum large-scale challenge mats were developed to provide a "playing field" on which the students can test their designs. Figure 6 shows the " $(\mathrm{Re}) \mathrm{New}$ Orleans" challenge mat. The mat provides context for the design challenge and a "course" that the students use to test their devices. This mat focuses on the Grand Challenge of "Restore and improve urban infrastructure", particularly in the wake of a natural disaster (i.e., Hurricane Katrina). 


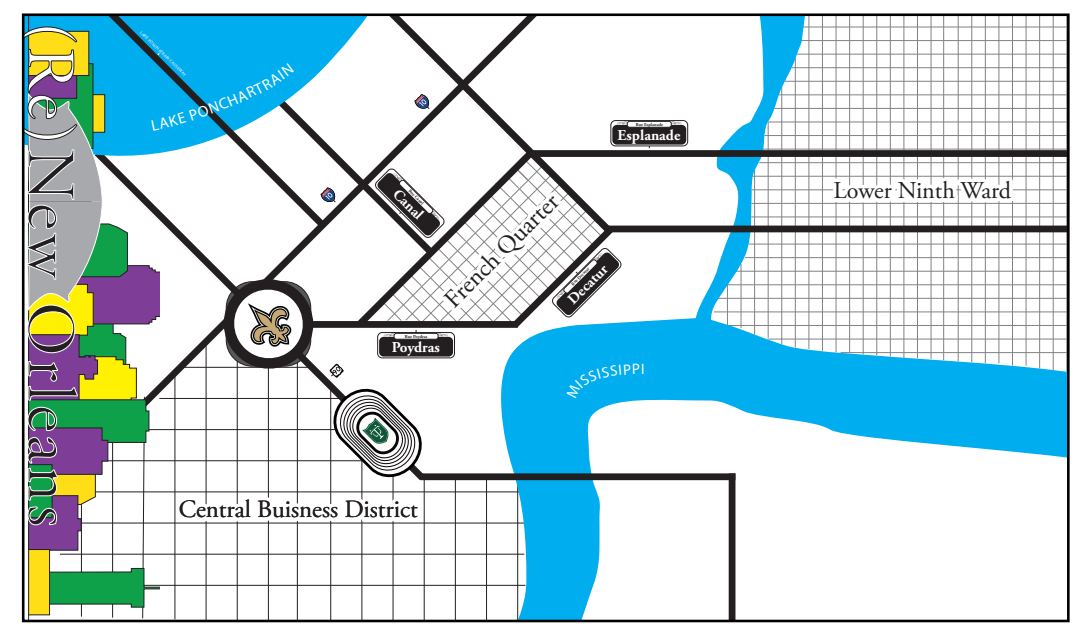

Figure 6: (Re)New Orleans Challenge Map

\section{Professional Development Documentation}

As part of the curriculum professional development documentation was created to assist the teachers with the curriculum. Figure 7 shows a sample of the agenda slide for the one-day PDI associated with the Grand Challenges of alternative energy and revitalizing infrastructure. In addition to providing content and experiences with the builds and programs, the PDI allows time for the participants to discuss pedagogy and to plan the semester's afterschool activities. Figure 8 is the suggested schedule for the curriculum.

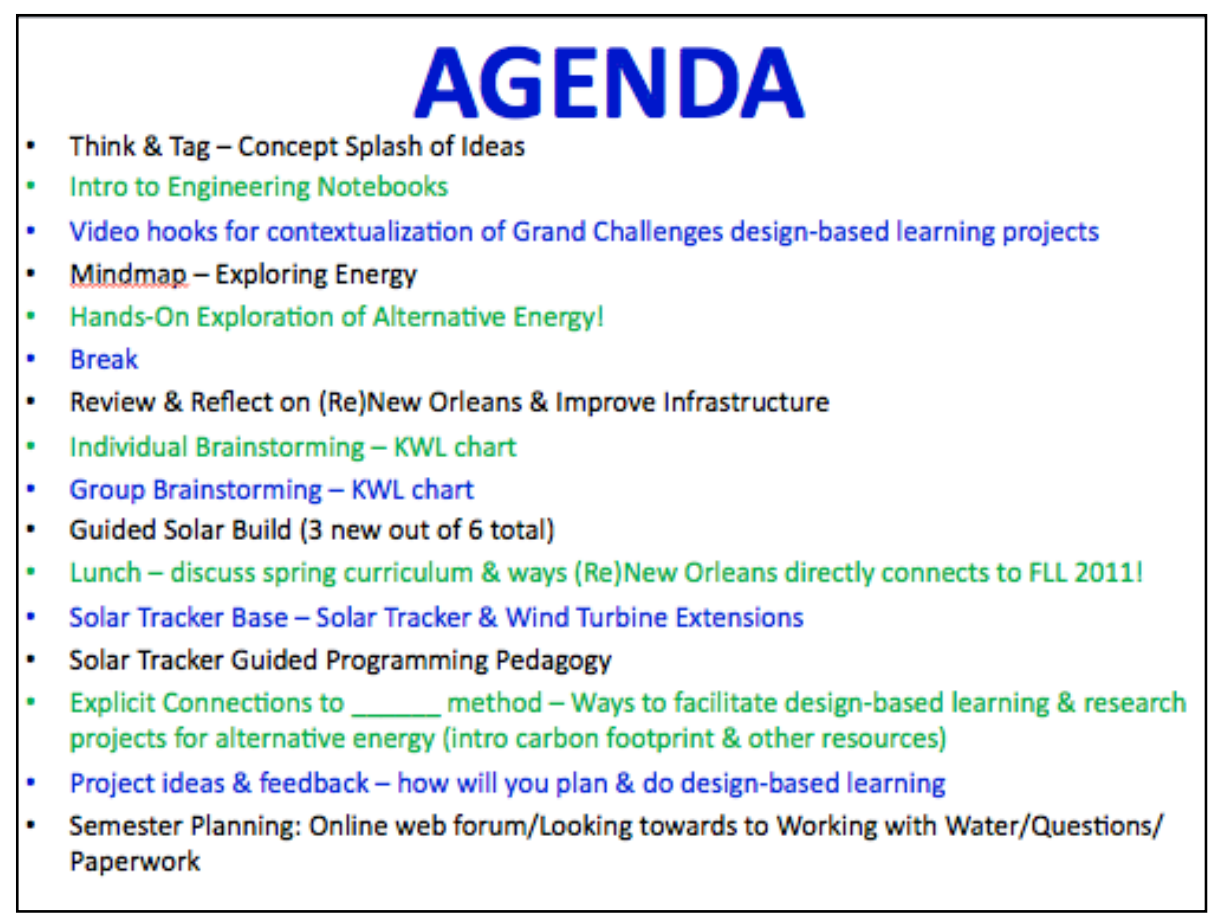

Figure 7: Agenda slide for PDI. 


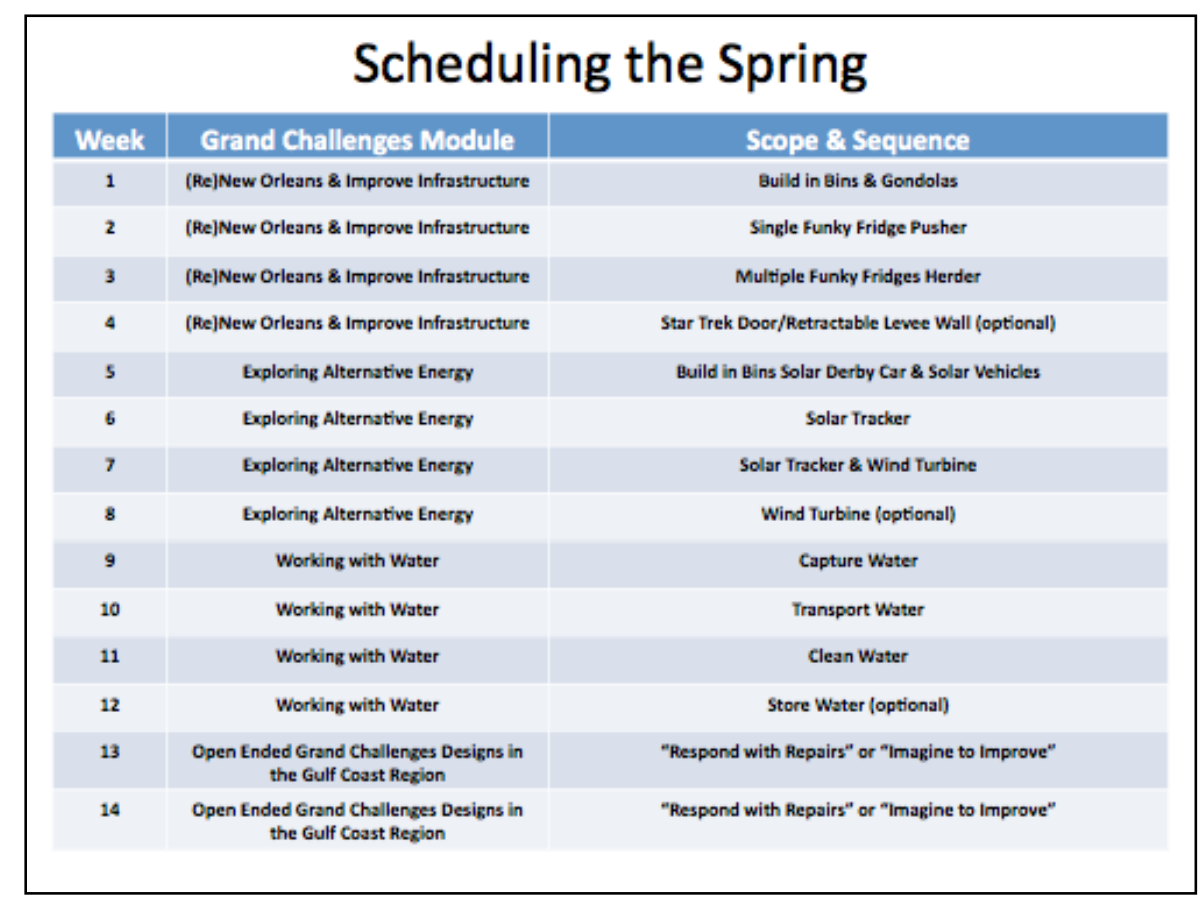

Figure 8: Suggested schedule for curriculum.

\section{Conclusion}

With our curriculum, students are identifying and seeking innovative solutions to some of our world's most pressing problems by designing engineering solutions. The curriculum includes the detailed structured LEGO ${ }^{\circledR}$ builds, specialized programming, curriculum design prompts, challenge mats, and professional development documentation. We continue to evolve the curriculum to address other Grand Challenges, such as "Provide access to clean water." As these curriculum materials develop, they will be made available on our website ${ }^{3}$.

\section{References}

[1] National Academy of Engineering Summit Series- Face the Challenge www.grandchallengesummit.org accessed Dec 20, 2010.

[2] Committee on Prospering in the Global Economy of the 21st Century: an agenda for American science and technology, Rising above the gathering storm: energizing and employing America for a brighter economic future, The National Academies Press, Washington, D.C. 2007.

[3] University of Texas. DTEACh Online. http://dteach.engr.utexas.edu/index.php/about-dteach-program, March 15, 2013.

[4] Crawford, R.H., Wood, K.L., Fowler, M., and Norrell, J., “An Engineering Design Curriculum for the Elementary Grades," ASEE Journal of Engineering Education, Vol. 83, No. 2, pp. 172-181, 1994.

[5] Talley, A., Schmidt, K., Wood, K., and Crawford, R., “Active Learning In Action, Understanding The Effects: What Happens When The New Wears Off In Teacher Training” Proceedings of 2008 American Society for Engineering Education Annual Conference, Pittsburgh PA, 2008

[6] Talley, A., Crawford, R., White C., and Wood, K. "Longitudinal Evaluation of Project-Based Professional Development Institute: Mixed Method Assessment with MBTI Type Correlations," Proceedings of 2011 American Society for Engineering Education Annual Conference, Vancouver, Canada, 2011

[7] Talley, A., Soontornvat, C., Fowler, M., and Schmidt, K., "Did It Work? Analysis Of Ways To Measure The Impact Of An After School Robotics Outreach Program.” Proceedings of 2009 American Society for Engineering Education Annual Conference, Austin, TX, 2009. 
[8] An Evaluation of the DTEACh Robolab Summer Institute for 2004 - Assessment of Instructional and Hands-on Learning Correlated with MBTI types. Proceedings of 2005 American Society for Engineering Education Annual Conference, Portland, OR, 2005

[9] Carberry, A. and M. Hynes., "Underwater Lego Robotics: Testing, Evaluation \& Redesign" Proceedings of 2007 American Society for Engineering Education Annual Conference, Honolulu, HI, 2007.

[10] Fleer, M., The Science of Technology: Young Children Working Technologically. International Journal of Technology and Design Education, 1999. 9(3): p. 269-291.

[11] LEGO Education Catalog, www.legoeducation.us, Jan 5, 2013.

[12] National Academy of Engineering, Challenges for Engineering, www.engineeringchallenges.org/, 2010. 